\title{
Effect of a topical diclofenac solution for relieving symptoms of primary osteoarthritis of the knee: a randomized controlled trial
}

\author{
Arthur A.M. Bookman, Kate S.A. Williams, J. Zev Shainhouse
}

Abstract

Background: Treatment of osteoarthritis with oral NSAID therapy provides pain relief but carries a substantial risk of adverse effects. Topical NSAID therapy offers an alternative to oral treatment, with the potential for a reduced risk of side effects. The objective of this trial was to assess the safety and efficacy of a topical diclofenac solution in relieving the symptoms of primary osteoarthritis of the knee.

Methods: We identified 248 men and women from southern Ontario with primary osteoarthritis of the knee and at least moderate pain. The patients were randomly assigned to apply 1 of 3 solutions to their painful knee for 4 weeks: a topical diclofenac solution $(1.5 \% \mathrm{wt} / \mathrm{wt}$ diclofenac sodium in a carrier containing dimethyl sulfoxide [DMSO]); a vehicle-control solution (the carrier containing DMSO but no diclofenac); and a placebo solution (a modified carrier with a token amount of DMSO for blinding purposes but no diclofenac). The primary efficacy end point was pain relief, measured by the Western Ontario and McMaster Universities (WOMAC) LK3.0 Osteoarthritis Index pain subscale. Secondary end points were improved physical function and reduced stiffness (measured by the WOMAC subscales), reduced pain on walking and patient global assessment (PGA). Safety was evaluated with clinical and laboratory assessments.

Results: In the intent-to-treat group the mean change (and 95\% confidence interval $[\mathrm{Cl}]$ ) in pain score from baseline to final assessment was significantly greater for the patients who applied the topical diclofenac solution ( -3.9 [ -4.8 to -2.9$])$ than for those who applied the vehicle-control solution $(-2.5[-3.3$ to $-1.7] ; p=0.023)$ or the placebo solution ( $-2.5[-3.3$ to -1.7$] ; p$ $=0.016$ ). For the secondary variables the topical diclofenac solution also revealed superiority to the vehicle-control and placebo solutions, leading to mean changes (and 95\% Cls) of -11.6 (-14.7 to $-8.4 ; p=0.002$ and 0.014 , respectively) in physical function, -1.5 ( -1.9 to $-1.1 ; p=0.015$ and 0.002 , respectively) in stiffness and $-0.8(-1.1$ to $-0.6 ; p=0.003$ and 0.015 , respectively) in pain on walking. The PGA scores were significantly better for the patients who applied the topical diclofenac solution than for those who applied the other 2 solutions ( $p=0.039$ and 0.025 , respectively). The topical diclofenac solution caused some skin irritation, mostly minor local skin dryness, in 30 (36\%) of the 84 patients, but this led to discontinuation of treatment in only $5(6 \%)$ of the cases. The incidence of gastrointestinal events did not differ between the treatment groups. No serious gastrointestinal or renal adverse events were reported or detected by means of laboratory testing.

Interpretation: This topical diclofenac solution can provide safe, site-specific treatment for osteoarthritic pain, with only minor local skin irritation and minimal systemic side effects.

CMAJ 2004;171(4):333-8

$\mathrm{O}$ steoarthritis is a degenerative joint disease affecting articular cartilage and underlying bone, commonly of the knee. ${ }^{1}$ Current treatment includes the oral use of NSAIDs, either nonselective or cyclooxygenase-2 (COX-2)-selective. These agents carry a substantial risk of clinically significant adverse effects, particularly on the gastrointestinal ${ }^{2,3}$ and renal systems. ${ }^{4}$ Although the incidence of gastrointestinal complications has been reported to be lower with COX-2-selective NSAIDs than with nonselective NSAIDs, ${ }^{5-7}$ the former have been linked to adverse renal effects ${ }^{8}$ and an increased risk of cardiovascular complications. ${ }^{9}$

The need for safer treatment of osteoarthritis has led to research into the topical use of NSAIDs. ${ }^{10-12}$ Recent reviews of the few published placebo-controlled studies suggest that topical NSAID therapy can relieve pain ${ }^{13-15}$ with few gastrointestinal side effects. ${ }^{16}$ Current practice guidelines advocate the use of topical therapy, including NSAIDs, in the management of osteoarthritis. ${ }^{17-19}$ A diclofenac solution containing the absorption enhancer dimethyl sulfoxide (DMSO) was developed for site-specific topical application. The objective of this study was to demonstrate that applying this solution to a painful knee with primary osteoarthritis could provide symptom relief with minimal systemic side effects.

\section{Methods}

Investigators from 7 medical centres in southern Ontario recruited patients for this study. The study was approved by the Committee for Research on Human Subjects of the Toronto Hospital's Medical Research Directorate and by similar committees at all other participating sites. After providing written informed consent, patients were screened and 248 were selected according to predetermined criteria. Inclusion criteria were as follows: primary osteoarthritis in at least $1 \mathrm{knee}$, verified radiologically within the previous 6 months and scored (as normal, minimal, moderate or marked) for joint-space narrowing and marginal osteophytes in the medial, lateral and patellofemoral compartments; ${ }^{20,21}$ at least moder- 
ate pain during the 2 weeks before random assignment to treatment, as identified with the Western Ontario and McMaster Universities (WOMAC) LK3.0 Osteoarthritis Index pain subscale; ${ }^{22}$ age 18 to 80 years; and, if female, could not or would not become pregnant. Exclusion criteria were as follows: secondary arthritis related to syphilitic neuropathy, ochronosis, metabolic bone disease or acute trauma; sensitivity to diclofenac, ASA or any other NSAID, DMSO, propylene glycol, glycerin or ethanol; clinically active renal, hepatic or peptic ulcer disease; history of alcohol or drug abuse; lactation; concomitant skin disease at the application site; corticosteroid use; use of another topical product at the application site; and oral use of an analgesic or glucosamine. Patients using NSAIDs or other prohibited medications underwent a 1-week washout of that medication before baseline assessment and random assignment to treatment. (This was a nonflare study: an increase [flare] in pain after washout of previous medication was not required.) The use of ASA $(\leq 325 \mathrm{mg} / \mathrm{d})$ was permitted for cardiovascular prophylaxis.

Patients were randomly assigned to receive treatment with 1 of 3 solutions: topical diclofenac solution $(1.5 \% \mathrm{wt} / \mathrm{wt}$ diclofenac sodium in a carrier containing DMSO [45.5\% wt/wt], propylene glycol, glycerin, ethanol and water [Pennsaid, Dimethaid Health Care Ltd.]); a vehicle-control solution consisting of the complete carrier, including DMSO (45.5\% wt/wt), but no diclofenac; and a placebo solution consisting of a modified carrier with a token amount of DMSO ( $4.55 \% \mathrm{wt} / \mathrm{wt}$ ) for blinding purposes but no diclofenac. A randomization list, computer-generated by an outside statistician, specified 60 patients per site in sub-blocks of 6 ; a list was later provided for an additional potential 20 patients per site at the first 3 sites. To ensure complete blinding, the randomization sequence was concealed from the investigators, support staff, patients and anyone directly involved in conducting the study, until final data lock. The study kits were prepared, labelled and numbered independently by the sponsor's quality assurance department. The 3 study solutions were identical clear, colourless liquids in opaque bottles; the labels differed only in patient identification number. The low concentration of DMSO in the placebo solution masked the garlic-like taste or odour sometimes reported with DMSO use. Patients applied 40 drops of solution (about $1.3 \mathrm{~mL}$ ) around the affected knee (10 drops to each side: front, back, medial and lateral), without rubbing, 4 times daily for 28 days. Compliance was verified by weighing bottles at the start of each weekly visit and calculating the number of grams applied per day per knee. Both knees were treated if painful and evaluated for treatment safety, but efficacy analysis was performed on data for only the designated study knee, which had the greater baseline pain score.

Patients completed a WOMAC assessment daily and a patient global assessment (PGA) weekly. The WOMAC LK3.0 Osteoarthritis Index is a validated, multidimensional questionnaire of defined reliability, content, construct validity and responsiveness. ${ }^{23-25}$ It consists of 24 questions (5 on pain, 17 on physical function and 2 on stiffness), each scored on a 5 -point Likert scale (0 to 4, 0 representing none). The PGA was scored from 0 to 4 (0 representing very good). Compassionate use of acetaminophen (up to two 325-mg tablets 4 times daily) was permitted for other body pain or residual knee pain throughout the washout and study periods, except during the 24 hours immediately before the baseline and final WOMAC assessments.

At the screening and final visits the patients provided urine and blood samples for routine analysis. Adverse events were recorded daily by the patients. In addition, at each weekly visit the investigator enquired about a checklist of gastrointestinal complaints commonly attributed to oral NSAID therapy. The knees were dermatologically assessed weekly; if erythema with induration was observed, the patient was withdrawn from the study. After the treatment period, the first 145 patients were tested for sensitization to their study solution (allergic contact dermatitis). ${ }^{26}$

The primary efficacy variable was the change from baseline to final assessment in the WOMAC subscale score for pain. Secondary variables were changes from baseline to final assessment in the WOMAC subscale scores for physical function and stiffness, as well as the PGA (sum of weekly scores). This core set of outcome measures follows the recommendations of the Outcome Measures in Arthritis Clinical Trials (OMERACT) III, ${ }^{27}$ the Osteoarthritis Research Society (OARSI) ${ }^{28}$ and the Group for the Respect of Ethics and Excellence in Science (GREES). ${ }^{29}$ Pain on walking (the first question of the WOMAC pain dimension) was analyzed a posteriori as a separate efficacy variable. The time course of pain relief was investigated for patients who responded to topical diclofenac treatment; responders were defined on the basis of the new OMERACT-OARSI set of responder criteria. ${ }^{30}$

A sample size of 40 patients per group was required to detect a difference between 2 treatment arms of 3 (standard deviation [SD] 5.0 ), 4 (SD 6.5) or 5 (SD 8.0) in the change in the WOMAC pain subscale score, with a power of $80 \%$ and a type $I(\alpha)$ error rate of 0.05 in a 2 -tailed test. Enrolment was planned for 50 patients per treatment group to allow for nonevaluable patients.

The intent-to-treat analysis group consisted of all randomly assigned, treated patients that met critical inclusion criteria of primary osteoarthritis (radiologic abnormalities and pain after washout of prior therapy). Some investigators failed to collect baseline WOMAC data for some patients after washout (pain data for 29 patients, physical function and stiffness data for 77 patients); day 1 data were substituted for the missing baseline data. To ensure sufficient power for subgroup analysis for the patients with complete baseline data, enrolment was increased to 80 patients per group. For any other missing WOMAC data, the last observation was carried forward. There was no imputation of safety data.

Baseline demographic variables, acetaminophen consumption, radiologic scores and compliance were analyzed by means of the $\chi^{2}$ test, Fisher's exact test or analysis of variance, as appropriate. Change in each WOMAC subscale score (final minus baseline) was analyzed by means of analysis of covariance, with the baseline score as a covariate. PGA was analyzed by means of analysis of variance. All statistical tests were 2 -sided and performed at the 0.05 level of significance.

\section{Results}

Of the 267 patients screened for the study 19 were excluded (5 were ineligible and 14 refused to participate). The remaining 248 were randomly assigned to treatment with 1 of the 3 study solutions (Fig. 1), and all of them received the allocated intervention. The baseline demographic characteristics of these 248 patients did not differ significantly between the treatment groups (Table 1). Of the patients in the topical diclofenac group 38\% had bilateral knee pain and treated both knees, as compared with $49 \%(p=0.17)$ of those in vehicle-control group and 51\% $(p=0.09)$ of those in the placebo group. Radiographic analysis showed no significant difference between the treatment groups in the distribution of severity of joint-space narrowing and marginal osteophytes, respectively, within each knee compartment (lateral, $p=0.72$ and 0.93 ; medial, $p=0.67$ and 0.47 ; patellofemoral, $p=0.36$ and 0.62 ). Compliance did not differ sig- 
nificantly between the treatment groups; the topical diclofenac group applied $95 \%(5.4 \mathrm{~g} / \mathrm{knee})$ of the planned dose of solution daily. Reasons for withdrawal from the trial (by 10, 14 and 15 patients in the topical diclofenac, vehiclecontrol and placebo groups, respectively) are given in Fig. 1.

Data for 1 patient in the vehicle-control group were excluded from the intent-to-treat analysis, in accord with the International Conference on Harmonisation ( $\mathrm{ICH})$ guidelines, ${ }^{31}$ because of failure to meet the major entry criterion of primary osteoarthritis (the patient had an injury to the anterior cruciate ligament). Seven patients did not answer the PGA question; their data were excluded from the PGA analysis.

For the primary efficacy variable, pain, the mean change (and $95 \%$ confidence interval [CT]) from baseline to final assessment was significantly greater with topical diclofenac treatment $(-3.9[-4.8$ to -2.9$])$ than with vehicle-control $(-2.5[-3.3$ to -1.7$] ; p=0.023)$ or placebo $(-2.5[-3.3$ to -1.7$] ; p=0.016)$ treatment. For the secondary variables treatment with topical diclofenac solution was also superior to the vehicle-control and placebo solutions, leading to mean changes of -11.6 ( -14.7 to $-8.4 ; p=0.002$ and 0.014 , respectively) in physical function, -1.5 ( -1.9 to $-1.1 ; p=0.015$ and 0.002 , respectively) in stiffness and -0.8 ( -1.1 to $-0.6 ; p=0.003$ and 0.015 , respectively) in pain on walking, and to a significantly better mean PGA score ( $p=0.039$ and 0.025 , respectively) (Table 2). Using analysis of covariance, with baseline score and number of knees treated as covariates, we found no influence of bilateral knee pain on the significance of these efficacy results. Among defined responders to topical diclofenac therapy the WOMAC pain score progressively declined during the first week of treatment, with a $42 \%$ reduction by the fourth day.

Mean acetaminophen consumption was lower in the topical diclofenac group (36.2 [SD 52.1] tablets) than in the vehicle-control (49.5 [SD 63.4]) and placebo (54.9 [SD 69.2]) groups, but the differences were not statistically significant.

The rate of patient dropout due to lack of effect was significantly lower in the topical diclofenac group (2/84 [2\%]) than in the vehicle-control $(8 / 80[10 \%] ; p=0.05)$ and placebo (10/84 [12\%]; $p=0.02)$ groups.

Minor skin dryness or flakiness at the application site was the most frequent adverse event, occurring in $36 \%$ $(30 / 84), 14 \%(11 / 80)$ and $1 \%(1 / 84)$ of the patients in the topical diclofenac, vehicle-control and placebo groups, respectively (Table 3 ). All skin reactions resolved promptly

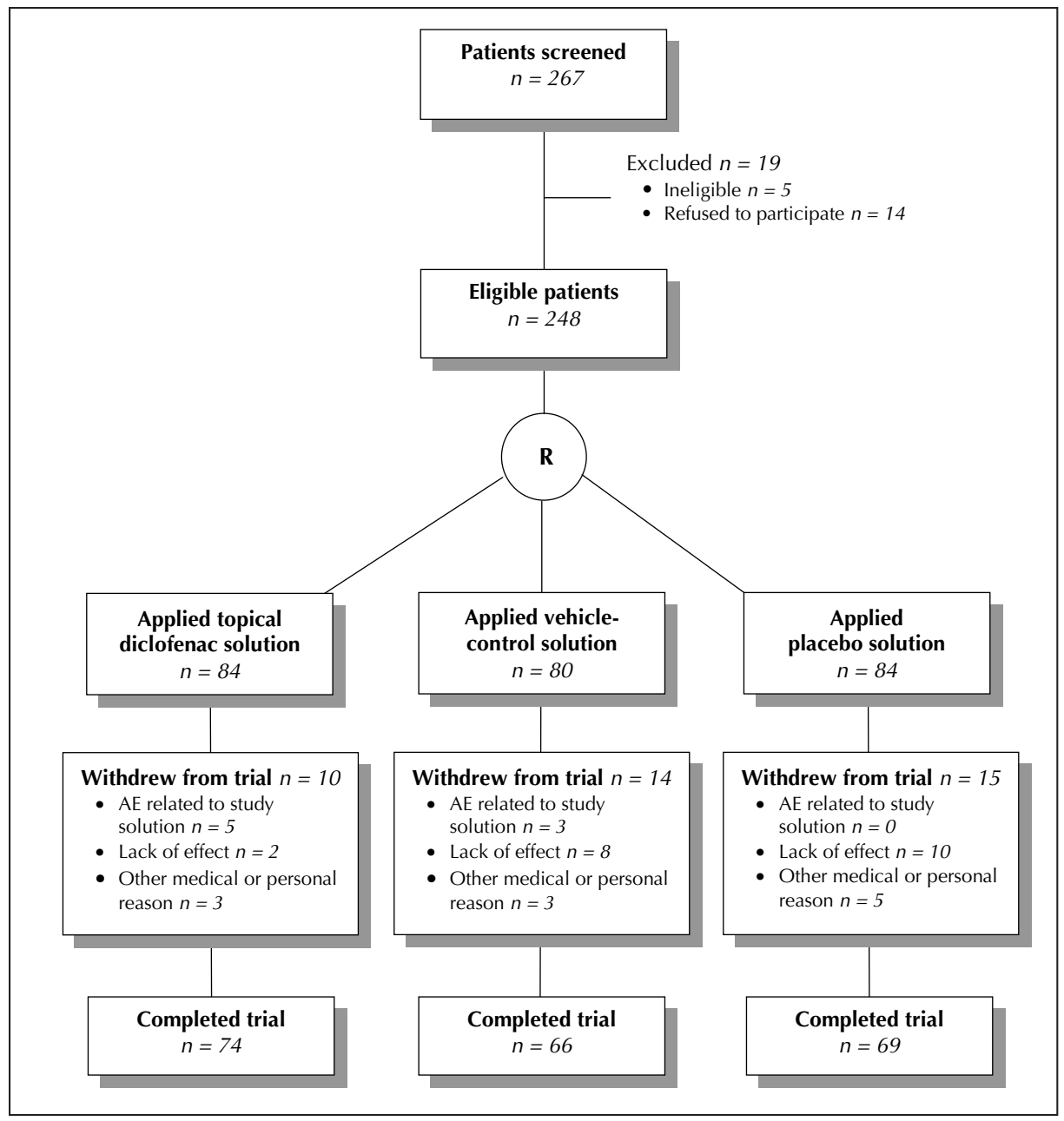

Fig. 1: Flow of patients through the study. $R=$ randomization, $A E=$ adverse event. 
upon withdrawal of treatment. No significant difference was noted in the incidence of gastrointestinal events. The rate of dropout due to a related adverse event was $6 \%$ $(5 / 84)$ in the topical diclofenac group, as compared with $4 \%(3 / 80 ; p=0.72)$ in the vehicle-control group and $0 \%$ $(0 / 84 ; p=0.06)$ in the placebo group. Testing for allergic contact dermatitis yielded negative results in 53/53, 46/47 and $45 / 45$ of the patients in the respective 3 groups.

A minor elevation in the serum level of alanine aminotransferase or aspartate aminotransferase, or both, was observed in 2 patients in the topical diclofenac group, 4 patients in the vehicle-control group and 1 patient in the placebo group. The elevation exceeded 1.2 times the upper limit of normal only when both levels were elevated (Table 4).

\begin{tabular}{|c|c|c|c|}
\hline \multirow[b]{2}{*}{ Characteristic } & \multicolumn{3}{|c|}{ Patient group } \\
\hline & $\begin{array}{c}\text { Topical diclofenac } \\
n=84\end{array}$ & $\begin{array}{l}\text { Vehicle-control* } \\
\quad n=80\end{array}$ & $\begin{array}{c}\text { Placebo } \dagger \\
n=84\end{array}$ \\
\hline Female, no. (and \%) & $52(62)$ & $54(68)$ & $51(61)$ \\
\hline Age, mean (SD), yr & $62.5(11.7)$ & $62.1(11.4)$ & $60.8(11.4)$ \\
\hline Weight, mean (SD), kg & $81.3(16.4)$ & $83.9(21.6)$ & $84.8(18.5)$ \\
\hline Height, mean (SD), m & $1.65(0.11)$ & $1.65(0.11)$ & $1.67(0.09)$ \\
\hline $\begin{array}{l}\text { Patients treating } 2 \text { knees, } \\
\text { no. (and \%) }\end{array}$ & $32(38)$ & $39(49)$ & $43(51)$ \\
\hline
\end{tabular}

Table 2: Efficacy-variable measures in the intent-to-treat group after 4 weeks of treatment

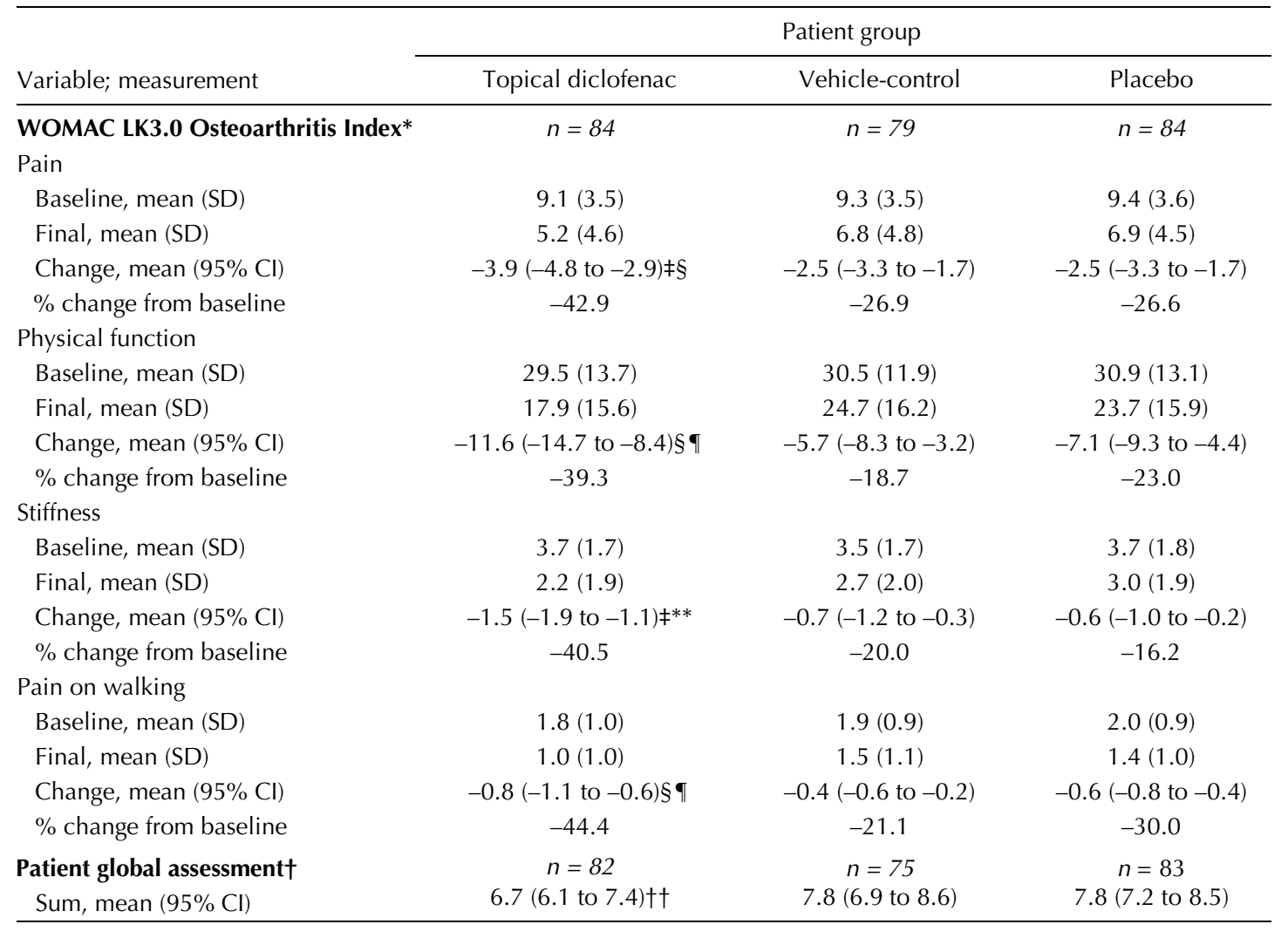

Note: WOMAC = Western Ontario and McMaster Universities, $\mathrm{Cl}=$ confidence interval.

*Subscales scored as follows, 0 representing none: pain, 0 to 20; physical function difficulty, 0 to 68 ; stiffness, 0 to 8 ; and pain on walking, 0 to 4 .

†Scored from 0 to 4,0 representing very good. The scores for weeks 1, 2, 3 and 4 were summed (maximum summed score is 16 ).

$\neq p<0.05$ and $\uparrow p<0.01$ compared with the value for the vehicle-control solution group.

$\S p<0.05$ and ${ }^{* *} p<0.01$ compared with the value for the placebo group.

$\dagger+p<0.05$ compared with the values for the 2 other groups. 


\section{Interpretation}

We have shown that 4 weeks of treatment with this topical diclofenac solution relieved the symptoms of primary knee osteoarthritis significantly better than the vehiclecontrol or placebo solution. The WOMAC subscale scores improved $42.9 \%$ for pain, $39.3 \%$ for physical function, $40.5 \%$ for stiffness and $44.4 \%$ for pain on walking. Among the responders to topical diclofenac therapy (those meeting OMERACT-OARSI criteria ${ }^{30}$ ), rapid onset of pain relief was observed during the first week of treatment. The primary adverse effects noted were reversible application-site skin reactions, predominantly dryness. The low rate of dropout due to related adverse events $(6 \%)$ in the topical diclofenac group, despite the prohibition of emollient use, suggests that these were tolerable, minor reactions.

Comparison of our efficacy results with those from previously published trials of topical NSAID treatment of osteoarthritis is difficult, as the latter were shorter and used different outcome measures. ${ }^{10,11,14,15}$ One placebo-controlled trial investigating 2 weeks of treatment of knee osteoarthritis with a topical diclofenac gel was conducted with the use of the WOMAC and found reductions in pain, physical function and stiffness of $37 \%, 26 \%$ and $17 \%$, respectively. ${ }^{12}$ The design of our study more closely parallels that of oral NSAID trials, including its being a large, randomized controlled trial with appropriate power, standardized radiologic and clinical entry criteria, and use of outcome measures standardized at OMERACT III as essential in osteoarthritis trials. ${ }^{27}$ Several reported investigations of oral diclofenac treatment for knee osteoarthritis have used the WOMAC. The percentage improvement in WOMAC subscale scores that we observed with topical diclofenac

\section{Table 3: Adverse events}

\begin{tabular}{|c|c|c|c|}
\hline \multirow[b]{2}{*}{ Adverse event } & \multicolumn{3}{|c|}{ Patient group; no. (and \%) of patients* } \\
\hline & $\begin{array}{c}\text { Topical diclofenac } \\
\qquad n=84\end{array}$ & $\begin{array}{c}\text { Vehicle-control } \\
n=80\end{array}$ & $\begin{array}{c}\text { Placebo } \\
n=84\end{array}$ \\
\hline \multicolumn{4}{|c|}{ At application site } \\
\hline Dry skin & $30(36) \dagger \ddagger$ & $11(14) \S$ & $1(1)$ \\
\hline Paresthesia & $12(14)$ & $18(22) \S$ & $5(6)$ \\
\hline Rash & $11(13) \Upsilon$ & $6(8)$ & $3(4)$ \\
\hline Pruritus & $9(11)$ & $6(8)$ & $3(4)$ \\
\hline \multicolumn{4}{|l|}{$\begin{array}{l}\text { Gastrointestinal } \\
\text { and other }\end{array}$} \\
\hline Constipation & $1 \quad(1)$ & $1(1)$ & $1(1)$ \\
\hline Diarrhea & 1 (1) & $2(2)$ & $3(4)$ \\
\hline Dyspepsia & $6(7)$ & $4(5)$ & $5(6)$ \\
\hline Nausea & 0 & $4(5)$ & $1(1)$ \\
\hline Vomiting & 0 & $1(1)$ & $1(1)$ \\
\hline Halitosis & $4 \quad(5)$ & $1(1)$ & 0 \\
\hline Body odour & $2 \quad(2)$ & 0 & 0 \\
\hline
\end{tabular}

*Some patients described several events or described a single event with several terms. $t p=0.001$ compared with the value for the vehicle-control group.

$\neq p<0.0001, \uparrow p<0.05$ and $\$ p<0.01$ compared with the value for the placebo group. therapy (39.3\% to $44.4 \%$ ) are similar to those reported for oral diclofenac treatment (35\% to $40 \%)^{32,33}$

The topical diclofenac formulation developed for this study contained DMSO,${ }^{34}$ which enhances the in vitro percutaneous absorption of diclofenac. ${ }^{35}$ Some of the adverse events in this study, particularly halitosis and body odour, can be attributed to the DMSO. DMSO is metabolized to the volatile gas dimethyl sulfide, which produces a garlic-like odour or taste when expired. The skin reactions, such as dry skin, appear to be due to the cutaneous presence of both DMSO and diclofenac. Although unsubstantiated claims of therapeutic efficacy for DMSO have been made, ${ }^{36}$ all efficacy variable comparisons in this study showed no therapeutic benefit of the vehicle-control solution (containing 45.5\% DMSO) over the placebo solution (containing $4.55 \%$ DMSO).

Although oral treatment with diclofenac can result in elevated serum levels of liver enzymes, only 1 patient using topical diclofenac in this study exhibited an elevation in alanine aminotransferase or aspartate aminotransferase that exceeded 1.2 times the upper limit of normal. Blood levels of diclofenac are up to 125 times lower with this topical solution $(12 \mathrm{ng} / \mathrm{mL})^{37}$ than those reported with standard oral diclofenac therapy.$^{38}$ Even prolonged exposure to large topical doses of DMSO ( $1 \mathrm{~g} / \mathrm{kg}$ daily for up to 3 months) rarely produced enzyme elevations. ${ }^{39}$ For comparison, in this study a $60-\mathrm{kg}$ person who applied diclofenac solution to both knees received only $0.06 \mathrm{~g} / \mathrm{kg}$ of DMSO daily.

One limitation of our study is the use of day- 1 efficacy scores for some patients missing baseline scores. After excluding the data for those patients (which left data for 218 patients in the pain subset and 170 in the physical-function and stiffness subsets), we found no effect on the conclusion of superiority of topical diclofenac therapy over vehicle-control treatment (pain, $p=0.009$; physical function, $p=0.002$; stiffness, $p=$ 0.023 ) and placebo treatment (pain, $p=0.004$; physical function, $p=0.004$; stiffness, $p=0.004$ ). Other limitations relate to study design. The trial length of 4 weeks may not be long enough to assess potential long-term safety concerns, particularly for the gastrointestinal system. Although comparing our efficacy results with those for reported trials of oral diclofenac therapy is justified, because the study design and outcome measures were similar, a direct-equivalence trial is required to fully assess the relative effects of the 2 types of treatment.

Table 4: Occurrence of elevated serum liver enzyme values

\begin{tabular}{lccc}
\hline & \multicolumn{3}{c}{ Patient group; no. of patients* } \\
\cline { 2 - 4 } Increased & $\begin{array}{c}\text { Topical diclofenac } \\
\text { enzyme value }\end{array}$ & $\begin{array}{c}\text { Vehicle-control } \\
n=74\end{array}$ & $\begin{array}{c}\text { Placebo } \\
n=75\end{array}$ \\
\hline ALT and AST & $1 \dagger$ & $2 \dagger$ & 0 \\
ALT only & 0 & 2 & 0 \\
AST only & 1 & 0 & 1 \\
\hline
\end{tabular}

Note: $\mathrm{ALT}=$ alanine aminotransferase, $\mathrm{AST}=$ aspartate aminotransferase.

*Includes patients whose values changed from within the normal range before the study to above normal with treatment (all values were $<2.5$ times the upper limit of normal). Patients without baseline or final laboratory data are excluded.

†The increase was $>1.2$ times the upper limit of normal. 
This randomized controlled trial has provided strong evidence for the efficacy and safety of this topical diclofenac solution. Future trials of greater treatment duration and a head-to-head comparison with oral NSAID therapy are required to address long-term safety and provide direct evidence of the efficacy and safety of this product in relation to standard therapies. None the less, given the current practice guidelines, this topical NSAID treatment is a reasonable new option for the management of osteoarthritis of the knee.

This article has been peer reviewed.

From the Division of Rheumatology, University Health Network, Western Division, University of Toronto, Toronto, Ont. (Bookman), and Dimethaid Health Care Ltd., Markham, Ont. (Williams, Shainhouse)

Competing interests: None declared for Arthur Bookman. Kate Williams and Zev Shainhouse were employees of Dimethaid Health Care Ltd. (as clinical research associate and medical director, respectively) when the study was conducted.

Contributors: Arthur Bookman, the principal investigator, contributed to patient recruitment, data acquisition and interpretation, and manuscript revision. Kate Williams supervised study conduct and data management and analysis; she also revised the manuscript. Zev Shainhouse contributed to study design and to data analysis and interpretation; he drafted and revised the manuscript. All authors approved the version of the manuscript to be published.

Acknowledgements: We acknowledge the collaboration and commitment of all study investigators and support staff, without whom the study would not have been possible: Philip A. Baer, Scarborough, Ont.; David C. Hoag, Peterborough, Ont.; Robert L. Ikeman, Toronto, Ont.; Noel A. Kerin, Port Hope, Ont.; Gordon D. Ko, Markham, Ont.; Peter R. Welsh, Toronto, Ont.; and D. Paul Willoughby, Woodstock, Ont. We also thank Lisa M. Thomas, Dimethaid Health Care Ltd., for help in preparing the manuscript.

\section{References}

1. Felson DT, Lawrence RC, Dieppe PA, Hirsch R, Helmick C, Jordan JM, et al. Osteoarthritis: new insights: Part 1 . The disease and its risk factors. Ann Intern Med 2000;133:635-46.

2. Gabriel SE, Jaakkimainen L, Bombardier C. Risk for serious gastrointestinal complications related to use of nonsteroidal anti-inflammatory drugs: a metaanalysis. Ann Intern Med 1991;115:787-96.

3. Wolfe MM, Lichtenstein DR, Singh G. Gastrointestinal toxicity of nonsteroidal antiinflammatory drugs. N Engl F Med 1999;340:1888-99.

4. Whelton A. Nephrotoxicity of non-steroidal anti-inflammatory drugs: physiologic foundations and clinical implications. Am 7 Med 1999;106(Suppl 5B):13S-24S.

5. Bombardier C, Laine L, Reicin A, Shapiro D, Burgos-Vargas R, David B, et al. Comparison of upper gastrointestinal toxicity of rofecoxib and naproxen in patients with rheumatoid arthritis. N Engl F Med 2000;343:1520-28.

6. Silverstein FE, Faich G, Goldstein JL, Simon LS, Pincus T, Whelton A, et al. Gastrointestinal toxicity with celecoxib vs nonsteroidal anti-inflammatory drugs for osteoarthritis and rheumatoid arthritis: the CLASS study: a randomized controlled trial. Celecoxib Long-term Arthritis Safety Study. 7AMA 2000;284:1247-55.

7. Langman MJ, Jensen DM, Watson DJ, Harper SE, Zhao PL, Quan H, et al. Adverse upper gastrointestinal effects of rofecoxib compared with NSAIDs. 7AMA 1999;282:1929-33.

8. Brater DC. Effects of nonsteroidal anti-inflammatory drugs on renal function: focus on cyclooxygenase-2-selective inhibition. Am 7 Med 1999;107 (Suppl 6A):65S-70S.

9. Mukherjee D, Nissen SE, Topol EJ. Risk of cardiovascular events associated with selective COX-2 inhibitors. 7AMA 2001;286:954-9.

10. Dreiser RL, Tisne-Camus M. DHEP plasters as a topical treatment of knee osteoarthritis - a double-blind placebo-controlled study. Drugs Exp Clin Res 1993;19:117-23.

11. Roth SH. A controlled clinical investigation of $3 \%$ diclofenac $/ 2.5 \%$ sodium hyaluronate topical gel in the treatment of uncontrolled pain in chronic oral NSAID users with osteoarthritis. Int 7 Tissue React 1995;17:129-32.

12. Grace D, Rogers J, Skeith K, Anderson K. Topical diclofenac versus placebo: a double blind, randomized clinical trial in patients with osteoarthritis of the knee. 7 Rheumatol 1999;26:2659-63.

13. Moore RA, Tramer MR, Carroll D, Wiffers PJ, McQuay HJ. Quantitative systematic review of topically applied non-steroidal anti-inflammatory drugs. BM7 1998;316:333-8.

14. Rosenstein ED. Topical agents in the treatment of rheumatic disorders Rheum Dis Clin North Am 1999;25:899-918.
15. Heyneman CA, Lawless-Liday C, Wall GC. Oral versus topical NSAIDs in rheumatic diseases: a comparison. Drugs 2000;60:555-74.

16. Evans JMM, McMahon A, McGilchrist M, White G, Murray F, McDevitt D. Topical non-steroidal anti-inflammatory drugs and admission to hospital for upper gastrointestinal bleeding and perforation: a record linkage case-control study. BM7 1995;311:22-6.

17. Scott DL, Shipley M, Dawson A, Edwards S, Symmons DPM, Woolf AD. The clinical management of rheumatoid arthritis and osteoarthritis: strategies for improving clinical effectiveness. Br 7 Rheumatol 1998;37:546-54.

18. American College of Rheumatology. Recommendations for the medical management of osteoarthritis of the hip and knee: 2000 update. American College of Rheumatology Subcommittee on Osteoarthritis Guidelines. Arthritis Rheum 2000;43:1905-15.

19. Jordan KM, Arden NK, Doherty M, Bannwarth B, Bijlsma JWJ, Dieppe P, et al. EULAR recommendations 2003: an evidence based approach to the management of knee osteoarthritis: Report of a task force of the Standing Committee for International Clinical Studies Including Therapeutic Trials (ESCISIT). Ann Rheum Dis 2003;62:1145-55.

20. Altman RD. Criteria for classification of clinical osteoarthritis. 7 Rheumatol 1991;18(Suppl 27):10-2.

21. Kellgren JH. The epidemiology of chronic rheumatism. Vol. II: Atlas of standard radiographs of arthritis. Oxford: Blackwell Scientific Publications; 1963.

22. Bellamy N. WOMAC osteoarthritis index - a user's guide. London (ON): London Health Sciences Centre; 1995.

23. Bellamy N, Buchanan WW, Goldsmith CH, Campbell J, Stitt L. Validation study of WOMAC: a health status instrument for measuring clinically-important patient-relevant outcomes following total hip or knee arthroplasty in osteoarthritis. F Orthop Rheumatol 1988;1:95-108.

24. Bellamy N, Buchanan WW, Goldsmith CH, Campbell J, Stitt LW. Validation study of WOMAC: a health status instrument for measuring clinically important patient relevant outcomes to antirheumatic drug therapy in patients with osteoarthritis of the hip or knee. 7 Rheumatol 1988;15:1833-40.

25. Bellamy N. Osteoarthritis clinical trials: candidate variables and clinimetric properties. 7 Rheumatol 1997;24:768-78.

26. Marzulli FN, Maibach HI, editors. Contact allergy: predictive testing in humans. In: Dermatotoxicology and pharmacology. Advances in modern toxicology. Vol 4 Washington (DC): Hemisphere Publishing; 1977. p. 353-72.

27. Bellamy N, Kirwan J, Boers M, Brooks P, Strand V, Tugwell P, et al. Recommendations for a core set of outcome measures for future phase III clinical trials in knee, hip and hand osteoarthritis. Consensus development at OMERACT III. 7 Rheumatol 1997;24:799-802.

28. Altman R, Brandt K, Hochberg M, Moskowitz R. Design and conduct of clinical trials in patients with osteoarthritis: recommendations from a task force of the Osteoarthritis Research Society. Osteoarthritis Cartilage 1996;4:217-43.

29. Group for the Respect of Ethics and Excellence in Science (GREES), Osteoarthritis Section. Recommendations for the registration of drugs used in the treatment of osteoarthritis. Ann Rheum Dis 1996;55:552-7.

30. Pham T, van der Heijde D, Lassere M, Altman RD, Anderson JJ, Bellamy N, et al. Outcome variables for osteoarthritis clinical trials: the OMERACTOARSI set of responder criteria. $\mathcal{F}$ Rheumatol 2003;30:1648-54.

31. Statistical principles for clinical trials. ICH harmonised tripartite guideline E9. Geneva: International Conference on Harmonisation of Technical Requirements for Registration of Pharmaceuticals for Human Use; 1998. Available: www.ich .org/MediaServer.jser?@_ID=485\&@_MODE=GLB (accessed 2004 May 25).

32. Yocum D, Fleischmann R, Dalgin P, Caldwell J, Hall D, Roszko P. Safety and efficacy of meloxicam in the treatment of osteoarthritis. Arch Intern Med 2000; $160: 2947-54$

33. McKenna F, Borenstein D, Wendt H, Wallemark C, Lefkowith JB, Geis GS Celecoxib versus diclofenac in the management of osteoarthritis of the knee. Scand F Rheumatol 2001;30:11-8.

34. Kligman AM. Topical pharmacology and toxicology of dimethyl sulfoxide Part I. 7AMA 1965;193:796-804.

35. Hewitt PG, Poblete N, Wester RC, Maibach HI, Shainhouse JZ. In vitro cutaneous disposition of a topical diclofenac lotion in human skin: effect of a multi-dose regimen. Pharm Res 1998;15:988-92.

36. Council on scientific affairs, American Medical Association. Dimethyl sulfoxide: controversy and current status - 1981. FAMA 1982;248:1369-71.

37. Hui X, Hewitt PG, Poblete N, Maibach HI, Shainhouse JZ, Wester RC. In vivo bioavailability and metabolism of topical diclofenac lotion in human volunteers. Pharm Res 1998;15:1589-95.

38. Voltaren product monograph. In: Canadian Pharmacists Association. Compendium of Pharmaceuticals and Specialties. Ottawa (ON); The Association; 2004. p. 2203-4

39. Brobyn RD. The human toxicology of dimethyl sulfoxide. Ann N Y Acad Sci 1975;243:497-506.

Correspondence to: Dr. J. Zev Shainhouse, Dimethaid Health Care Ltd., 1405 Denison St., Markham ON L3R 5V2;

fax 905 415-0827 